\title{
APLIKASI SMART CARD PADA METERAN AIR DIGITAL PRABAYAR BERBASIS ARDUINO MEGA 2560
}

\author{
Adhila Rafik, Yuniarto \\ Program Studi Diploma III Teknik Elektro \\ Fakultas Teknik Universitas Diponegoro
}

\begin{abstract}
Adhila Rafik, Yuniarto, in paper smart card application in prepaid digital water meter based on arduino mega 2560 explain that water is a daily necessity, to get a decent clean water to be used, we can use the services of the service taps to get water, but the post-pay payment method used taps raises its own problems, namely the problem of payment arrears. To resolve the issue of payment methods can be converted to a prepaid system, so the use of water dilakuakn after the user makes a payment in advance, many prepaid methods, one of which is the smart card is a plastic card in which there is a microcontroller chip that makes it possible to encrypt the data that there didalamya so not just anyone can read and menulisa data into the card, the use of smart cards as a payment method for a digital prepaid water meter taps, can overcome the problem of payment arrears. Because the use of RFID technology allows the User just close the smart card reader to its user.
\end{abstract}

Keywords: smart cards, prepaid, RFID

\section{PENDAHULUAN}

Salah satu tuntutan yang dihadapi dunia industri jasa saat ini adalah menciptakan sistem pelayanan terhadap publik yang memberikan kemudahan dalam tukar-menukar informasi, transaksi, dengan tingkat keamanan yang tinggi. Masalah ini juga dapat dijumpai pada lingkungan kerja apa saja yang membutuhkan faktor-faktor, seperti : mobilitas tinggi, keamanan data, ketangguhan terhadap gangguan, kestabilan, dan unjuk kerja yang tinggi. Faktor-faktor tersebut memegang peranan penting dalam kelangsungan hidup industri karena berpengaruh langsung pada mutu produk atau layanan yang diberikan

Smart card diciptakan untuk menjadi solusi bagi masalah tersebut. Teknologi ini menawarkan banyak manfaat signifikan bagi para penyedia dan pengguna jasa, sekaligus menawarkan tantangan bagi siapa saja yang ingin mengembangkan inovasi ini lebih lanjut. Mobilitas tinggi didapatkan dari ukuran fisik yang kecil dengan dimensi chip hanya 85,6 mm x $54 \mathrm{~mm}$. Keamanan data didukung oleh adanya mikroprosesor dalam chip yang dapat melakukan proses enkripsi data yang disimpan. Kestabilan dan kecepatan dapat dioptimalkan dengan makin banyaknya bahasa pemrograman yang mendukungnya.

Melihat hal tersebut, maka dapat dikembangkan sistem pembayaran prabayar dengan smart card yang diaplikasikan dalam meteran air digital prabayar pada PDAM.

Smart card sebagai alat bayar meteran air digital prabayar, sehingga pengguna dapat mengisi ulang seperti halnya mengisi ulang pulsa telepon. Hal ini akan menjadikan masalah yang dihadapi seprti penunggakan pembayaran dan kesalahan pencatatan meteran dapat dihindari.

\section{PERENCANAAN SISTEM}

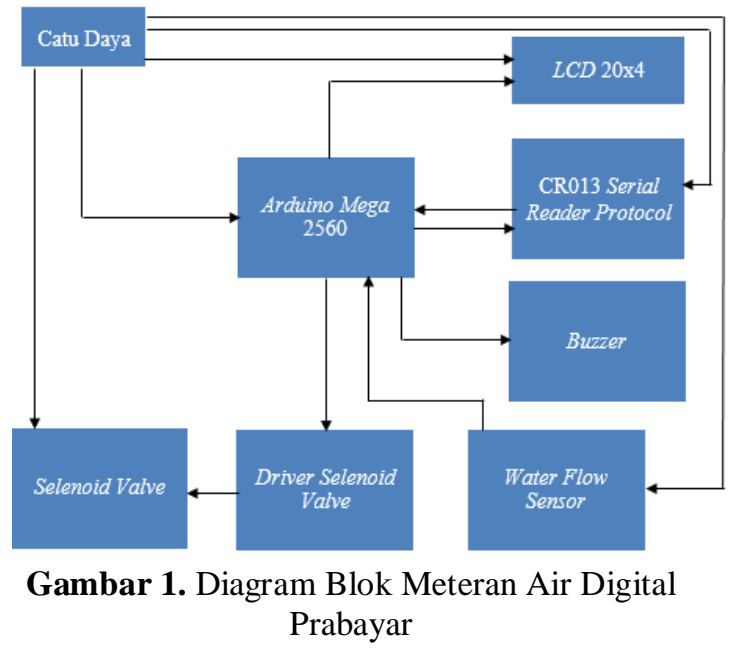

Sesuai diagram blok diatas maka pembuatan program dapat dibagi menjadi beberapa bagian seperti berikut :

- Program pembacaan smart card dengan CR013 Serial Reader Protocol, sebagai pengontrol/pengatur banyaknya jumlah air yang akan digunakan. Kemudian jumlah air yang tersimpan dalam smart card akan terbaca oleh arduino dan kemudian digunakan untuk membatasi jumlah pemakaian air.

- Program pembacaan water flow sensor, sebagai sensor aliran air berfungsi untuk mengetahui jumlah liter air yang telah digunakan, sehingga jika jumlah liter air yang digunakan sudah mencapai batas maka aliran air akan diputus oleh selenoid valve dan buzzer akan berbunyi.

- Program LCD 20x4, sebagai penampil jumlah liter air yang terpakai dan menampilkan batas pemakaian. 


\section{Aplikasi smart card pada Meteran Air Digital Prabayar}

Pengaplikasian smart card pada meteran digital prabayar adalah sebagai pengendali jumlah debit/liter air yang akan digunakan, kartu smart card akan di isi dengan nominal tertentu, dan pembacaan pada alat meteran air digital akan terbaca nominal tersebut dan menunjukan jumlah liter air yang telah di isikan.

Modul yang digunakan untuk membaca kartu Mifare salah satunya adalah CR-013F. Modul buatan China berukuran $42 * 18 \mathrm{~mm}$ ini bekerja dengan tegangan $4.5 \mathrm{~V}-5.5 \mathrm{~V}$. Antarmuka yang digunakan adalah UART TTL232 dengan pemakaian daya sekitar 70-120 mA. Modul ini cocok digunakan untuk aplikasi pembaca tag portabel dengan daya baterai. Kali ini akan kita bahas bagaimana menggunakan modul ini, mulai dari cara merakitnya hingga membuat program untuk membaca kartu/tag RFID Mifare 13.56MHz.

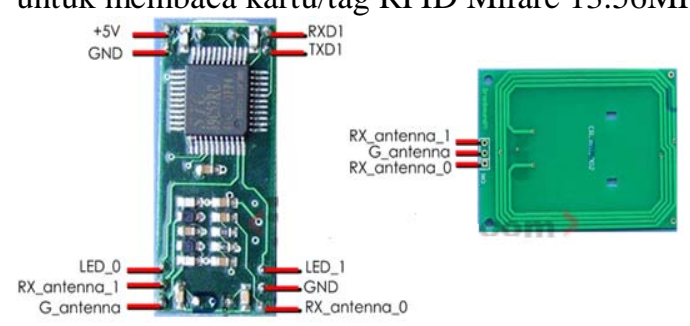

Gambar 2. CR013 Serial reader protocol(kiri), dan Antenna(kanan)

Gambar 3 menunjukan pin yang terdapat pada modul reader RFID CR013, dari pin VCC, GND, TXD1, RXD1, RX antenna 1, RX antenna 2, G antenna, LED 1 dan LED Setelah antena terpasang, selanjutnya adalah menghubungkan modul ini dengan unit pemroses, pada meteran air digital prabayar digunakan Arduino Mega 2560 yang menggunakan mikrokontroler Atmrga 2560. Mikrokontroler jenis lain dapat digunakan selama memiliki port serial. PC juga dapat dihubungkan dengan modul ini. Hubungan dengan mikrokontroler dapat dilihat pada skematik rangkaian yang terdapat pada Gambar 4.

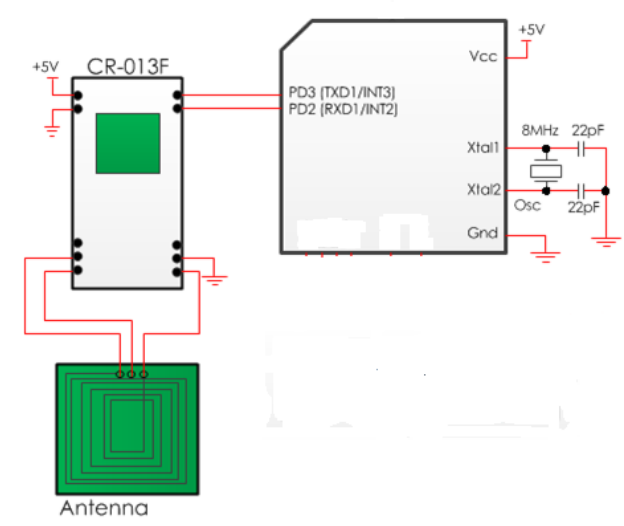

Gambar 4. Diagram Skematik Pembaca RFID
Gambar 4 menunjukan wearing arduino dengan modul CR-013 serial reader protocol, yang terhubung dengan port comunication(TXD dan $\mathrm{RXD).}$

\section{Prosedur Membaca atau menulis kartu}

Ada beberapa langkah yang harus dilakukan untuk dapat membaca atau menulis kartu, yaitu:

- Memerikas tipe kartu.

- Meminta nomor seri kartu.

- Memilih kartu berdasarkan

o nomor seri yang didapatkan

o pada langkah nomor 2 .

- $\quad$ Aunthentifikasi Mifare 2.

- Proses baca atau tulis kartu

Proses tersebut diatas dapat dilakukan ketika kartu masih berada pada area baca, namun ketika kartu keluar dari area baca maka langkah 1 -4 harus diulang.

\section{Protocol Data \\ Protokol data dari PC/Mikrokntroler ke reader}

Paket data diawali dengan Header (2byte) yang terdiri dari bilangan hex \&HAA dan \&HBB, kemudian diikuti panjang data (Data Length) yaitu dimulai dari Id node hingga checksum. Panjang data ini terdiri dari dua byte dimulai dari Low Byte kemudian baru High Byte. Selanjutnya adalah ID node, merupakan alamat tujuan (reader) diawali low byte terlebih dahulu baru high byte. Untuk membaca seluruh reader yangterpasang bisa diisikan dengan \&H00 dan \&H00. Dua byte berikutnya adalah fungsi perintah (Function), isinya disesuaikan dengan perintah yang akan dikirim seperti pada tabel 2.3. Yang terakhir adalah Checksum yang akan dihitung dengan menerapkan operator XOR semua data mulai dari ID node hingga sebelum checksum.

\begin{tabular}{|c|c|c|c|c|c|}
\hline $\begin{array}{l}\text { Header } \\
\text { (2 byte) }\end{array}$ & $\begin{array}{c}\text { Data Length } \\
\text { (2 byte) }\end{array}$ & $\begin{array}{c}\text { D node } \\
\text { (2 byte) }\end{array}$ & $\begin{array}{c}\text { Function } \\
\text { (2 byte) }\end{array}$ & $\begin{array}{c}\text { Data } \\
(00 \mathrm{H}-0 \mathrm{DH})\end{array}$ & $\begin{array}{c}\text { Checksum } \\
\text { (1 byte })\end{array}$ \\
\hline
\end{tabular}

Gambar 5. Protokol Data dari PC/Mikrokontroler ke reader

\section{Protokol datadari reader ke PC/Mikrokontroler}

Paket data diawali dengan Header (2byte) yang terdiri dari bilangan hex \&HAA dan \&HBB, kemudian diikuti panjang data (Data Length) yaitu dimulai dari ID node hingga checksum. Panjang data ini terdiri dari dua byte dimulai dari Low Byte kemudian baru High Byte. Selanjutnya adalah ID node, merupakan alamat tujuan (reader) diawali low byte dulu baru high byte. Dua byte berikutnya adalah fungsi perintah (Function), isinya sesuai dengan perintah yang dikirimkan reader. 


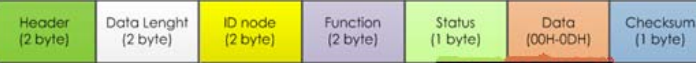

Gambar 6. Protokol data dari reader ke PC/Mikrokontroler

Setelah mengetahui bagaimana reader RFID dan Mikrokontroler berkomunikasi, selanjutnya adalah membuat program mengakses RFID readermrngunakan bahasa $\mathrm{C}$. Rutin yang dibuat pertama kali adalah rutin untuk mengirim perintah (request) dari mikro ke reader mengikuti protokol pada gambar berikut.

\begin{tabular}{|c|c|c|c|c|c|}
\hline $\begin{array}{l}\text { Header } \\
\text { (2 byte) }\end{array}$ & $\begin{array}{c}\text { Data Length } \\
\text { (2 byte) }\end{array}$ & $\begin{array}{c}\text { ID node } \\
\text { (2 byte) }\end{array}$ & $\begin{array}{c}\text { Function } \\
\text { (2 byte) }\end{array}$ & $\begin{array}{c}\text { Data } \\
(00 \mathrm{H}-\mathrm{ODH})\end{array}$ & $\begin{array}{c}\text { Checksum } \\
\text { (1 byte) }\end{array}$ \\
\hline
\end{tabular}

Gambar 7. Protokol Request Function

Berikutnya membuat sub procedure untuk mengirimkan perintah ke reader. Dua byte pertama yang dikirim merupakan sebuah konstanta \&HAA dan \&HBB, kemudian diikuti panjang data dimulai dari low byte dan high byte. Perintah Shift digunakan untuk menggeser bilangan hexa variabel Panjang karena yang dikirim dahulu adalah low byte baru high byte. Kemudian mengirim beberapa kode Fungsi Perintah yang tersimpan dalam variabel $X$ satu persatu. Selama mengirim ke reader, program juga menghitung checksum yaitu dengan menerapkan operatorXOR pada tiap data yang dikirim. Terakhir mikro mengirim adalah Checksum .Potongan programnya sebagai berikut void kirim (unsigmed int panjang, unsigned char const tpesan, unsigned char chk) (

unsigned char chksum $=0, i$

Serial. write (0xÅA);

Serial. write (0xBB)

if $\{\mathrm{chk}==0$ )

panjangt+

Serial.write (panjang) : (prinin panjang date low byte

Serial.write (panjangos8); / kirim nanjang data high hyte

for $(i=0 ; i<$ (panjang-1):i+t) //kirim pesan sebanyak pesa $2(1=0 ; 1<($ panjang- 1$) ; 1+1)$

Serial. write (pesan[i])

chksum=chksumenesan [i]; , thitung checksul

Serial, write (chksum)

Rutin (sub procedure) yang kedua adalah kode program untuk mengambil respon yang dikirimkan oleh reader kepada mikro ketika suatu perintah dikirim ke reader. Protokol respon reader mengikuti format seperti pada Gambar 3.7 berikut.

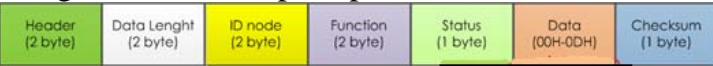

Gambar 8. Protokol respon reader

Program diawali dengan mengambil 2 byte Header yang terdiri dari \&HAA dan \&HBB. Pertama harus dicek apakah data serial yang diterima berupa \&HAA, jika ya, cek kembali byte kedua apakah \&HBB. Jika kedua syarat terpenuhi, langkah selanjutnya mengambil 2 byte berupa Panjang data. Panjang data yang diperoleh digunakan untuk variabel counting pengambilan data Status dan Data,pada contoh ini Status dan
Data disimpan pada variabel reader data() . Bentuk potongan programnya seperti berikut:

void ambil_respon(void)

\{

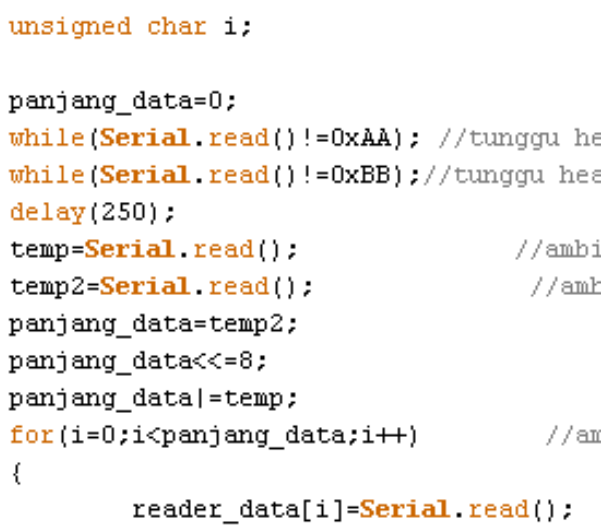

Setelah kedua sub procedure diatas dibuat, kemudian bisa digunakan untuk membaca kartu smart card.

\section{Pembacaan Water Flow Sensor}

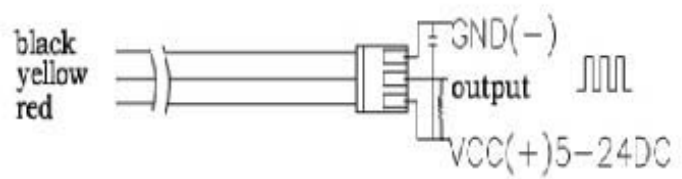

Gambar 9. Wiring Diagram Water Flow Sensor

Gambar 3.8 menunjukan pengkabelan water flow sensor, output sensor berupa pulsa ang akan dibaca oleh arduino.Pertama adalah menginisialisasi variabel dan pin yang akan digunakan pada program pembacaan water flow sensor sebagai berikut :

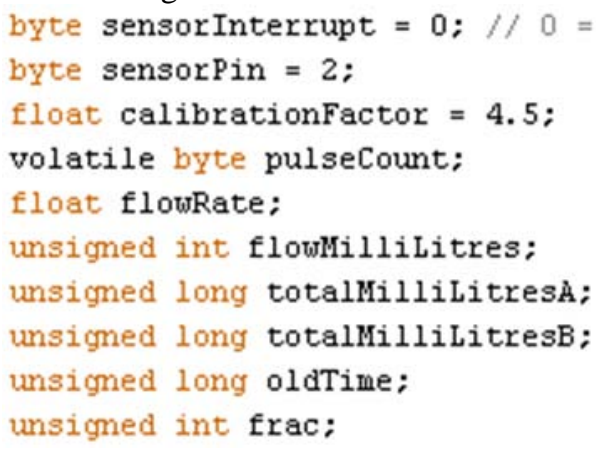

Untuk input sensor menggunakan pin 2, dengan menggunakan interrupt 0 pada arduino mega, pengguanaan interrupt pada rutin ini dimaksudkan untuk menjalankan program penghitung pulsa yang keluar dari water flow sensor akibat sensor effect hall dan kemudian akan disimpan dalam variabel "pulseCount", , berikut rutinnya : 


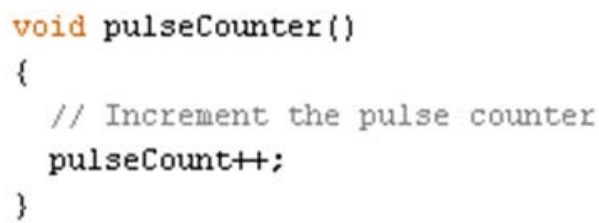

Setelah pulsa diketahui maka langkah selanjutnya adalah menghitung kecepatan aliran air dan liter air yang telah lewat, berikut adalah rutinnya:

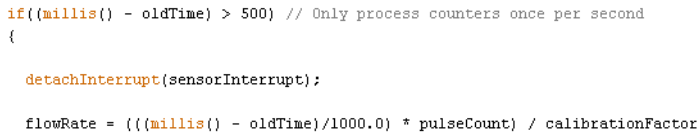

Rutin diatas adalah menghitung aliran air yang kemudian disimpan dalam variabel"flowRate", setelah aliran air diketahui maka dapat menghitung jumlah liter air yang telah lewat, berikut rutinnya :

$$
\text { flowillibitres }=(\text { flowRate } / 60) * 1000 \text {; }
$$

\section{// Add the millilitres passed in this second totalMilliLitresA $+=$ flowMilliLitres; totalMilliLitresB $+=$ flowMilliLitres;}

Program diatas mencari liter yang telah melewati water flow sensor, dan kemudian menyimpannya dalam variabel "totalMilliLitresA" dan "totalMilliLitresB”. Dengan rutin diatas maka pembacaan water flow sensor dapat dilakukan.

\section{Program LCD 20x4}

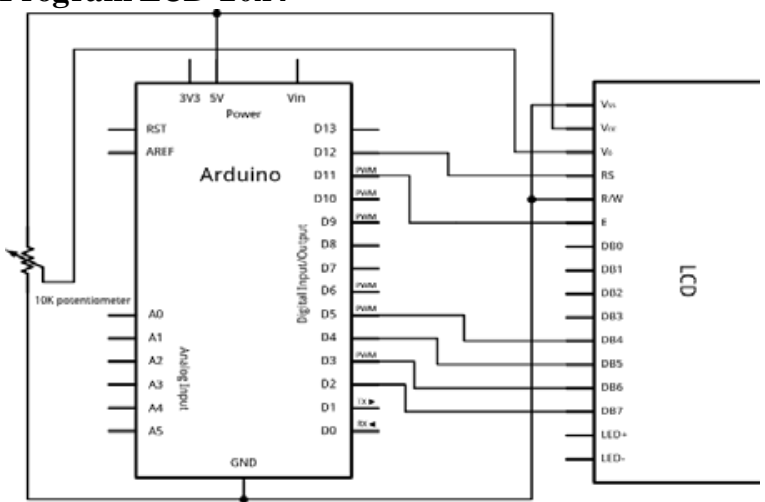

Gambar 10. Wiring diagram $L C D$

Gambar 10 menunjukan wiring LCD dengan port Digital I/O pad arduino. Sebagai media penampil mengunakan LCD 20x4 yang akan menampilkan kecepatan aloran air, jumlah liter air yang terpakai dan batas pemakaian air, pada tampilan LCD ini terdapat 2 penghitung liter air, yang pertama untuk menhitung jumlah liter air yang telah terpakai, dan yang kedua adalah menghitung sisa liter yang dapat terpakai, berikut adalah rutinnya:

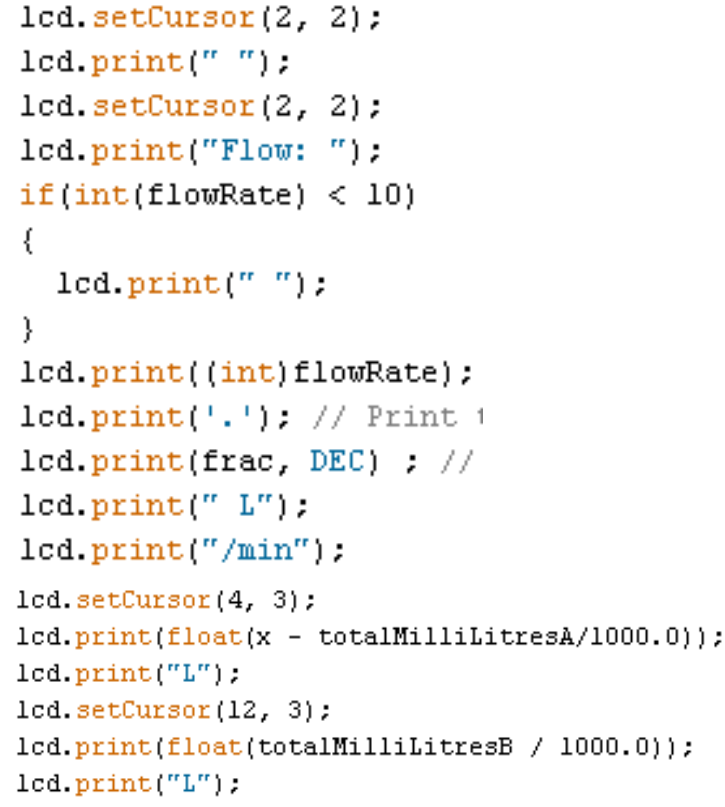

Diagram alir dari sistem secara keseluruhan ditunjukkan pada gambar 11 .

\section{PENGUKURAN DAN PENGUJUAN Pengukuran Catu Daya}

Pengukuran rangkaian catu daya pada dasarnya bertujuan untuk mengetahui tegangan keluaran dari rangkaian catu daya agar tegangan keluaran dapat stabil sebagai catu daya pada masing-masing modul. Pada sistem ini menggunakan rangkaian catu daya dengan tegangan output sebesar $18 \mathrm{~V}$ dan $12 \mathrm{~V}$. Titik pengukuran yang dilakukan meliputi input trafo yaitu dari tegangan jala-jala PLN, output dari trafo yaitu tegangan PLN yang telah diturunkan oleh trafo step down, keluaran dioda sebagai keluaran setelah tegangan disearahkan, input dan output regulator, serta tegangan keluaran akhir.

Tabel 1. Pengukuran Catu Daya

\begin{tabular}{|c|l|c|}
\hline No. & \multicolumn{1}{|c|}{ Bagian Yang Diukur } & Tegangan \\
\hline 1 & Tegangan Input Trafo & $220 \mathrm{~V}_{A C}$ \\
\hline 2 & Tegangan Output Trafo 1 & $12 \mathrm{~V}_{A C}$ \\
\hline 3 & Tegangan Output Trafo 2 & $18 \mathrm{~V}_{\mathrm{AC}}$ \\
\hline 4 & Tegangan Output Dioda 1,2 & $12 \mathrm{~V}_{\mathrm{DC}}$ \\
\hline 5 & Tegangan Output Dioda 3,4 & $18 \mathrm{~V}_{\mathrm{DC}}$ \\
\hline 6 & Tegangan Output IC 7808 & $7,7 \mathrm{~V}_{D C}$ \\
\hline 7 & Tegangan Output IC 7812 & $11,7 \mathrm{~V}_{D C}$ \\
\hline
\end{tabular}




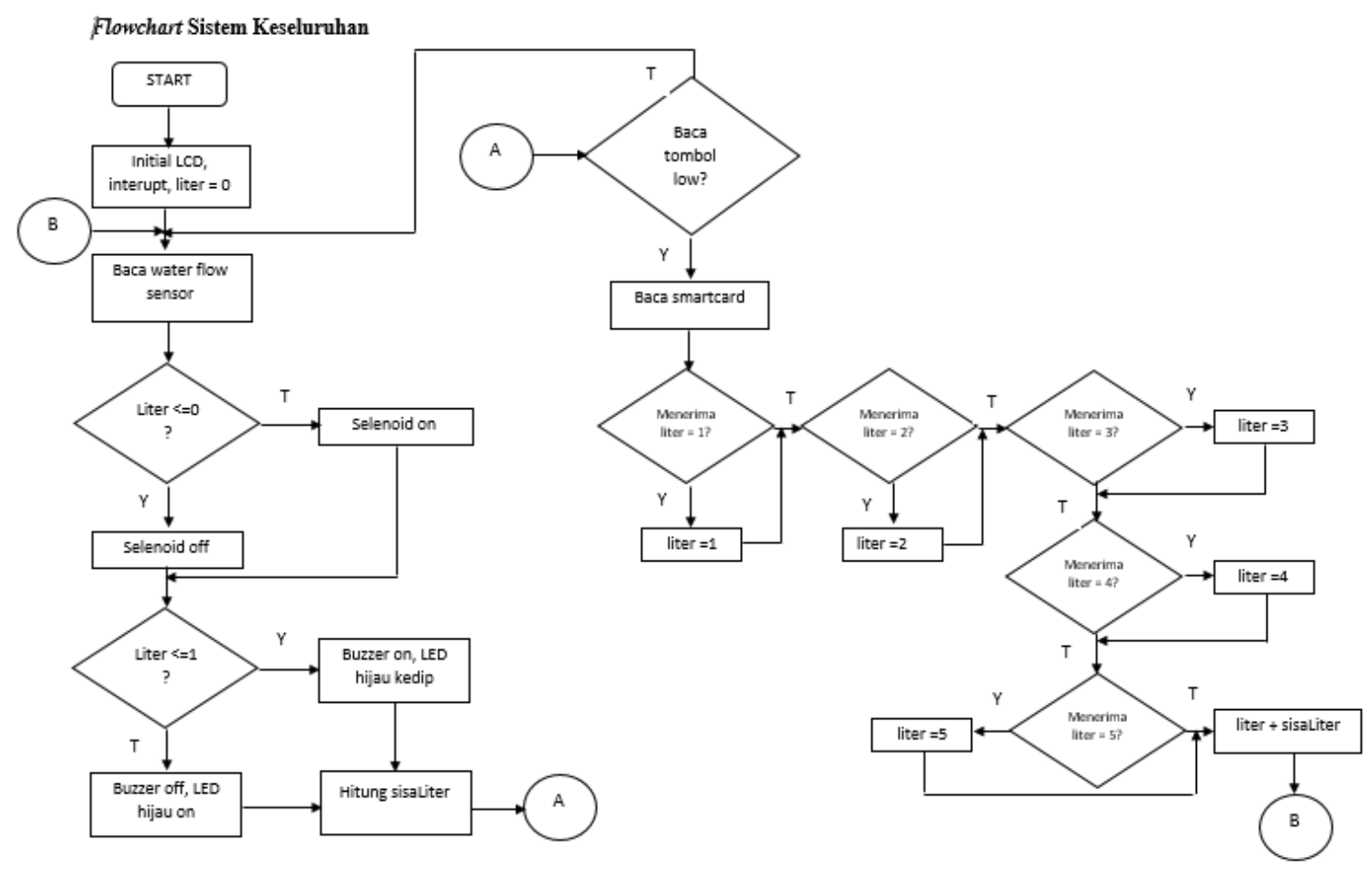

Gambar 11. Diagram alir sistem keseluruhan

\section{PengukuranRangkaian Mikrokontroler Arduino}

Mega

Tabel 2. Hasil Pengukuran Kondisi Logika Port Mikrokontroler Arduino

\begin{tabular}{|c|c|c|c|c|c|c|c|}
\hline \multirow{2}{*}{ Pin } & \multirow{2}{*}{ Vin } & \multirow{2}{*}{$\begin{array}{c}\mathrm{H} / \\
\mathrm{L}\end{array}$} & \multicolumn{5}{|c|}{ Tegangan Pada Tian Pengujian Port Digital (V) } \\
\hline & & & 0 & 1 & 2 & 3 & 4 \\
\hline \multirow{2}{*}{ Dig22 } & \multirow{12}{*}{$5 \mathrm{~V}$} & $\mathrm{H}$ & 4,2 & 4.2 & 4.2 & 4.2 & 4.2 \\
\hline & & $\mathrm{L}$ & 0 & 0 & 0 & 0 & 0 \\
\hline \multirow{2}{*}{ Dig24 } & & $\mathrm{H}$ & 0 & 0 & 0 & 0 & 0 \\
\hline & & $\mathrm{L}$ & 0 & 0 & 0 & 0 & 0 \\
\hline \multirow{2}{*}{ Dig26 } & & $\mathrm{H}$ & 2 & 2 & 2 & 2 & 2 \\
\hline & & $\mathrm{L}$ & 0 & 0 & 0 & 0 & 0 \\
\hline \multirow{2}{*}{ Dig28 } & & $\mathrm{H}$ & 2,4 & 2,4 & 2,4 & 2,4 & 2,4 \\
\hline & & L & 0 & 0 & 0 & 0 & 0 \\
\hline \multirow{2}{*}{ Dig30 } & & $\mathrm{H}$ & 2 & 2 & 2 & 2 & 2 \\
\hline & & $\mathrm{L}$ & 0 & 0 & 0 & 0 & 0 \\
\hline \multirow{2}{*}{ Dig32 } & & $\mathrm{H}$ & 1,9 & 1,9 & 1,9 & 1,9 & 1,9 \\
\hline & & $\mathrm{L}$ & 0 & 0 & 0 & 0 & 0 \\
\hline
\end{tabular}

\begin{tabular}{|c|c|c|c|c|c|c|c|}
\hline \multirow{2}{*}{ Pin } & \multirow{2}{*}{ Vin } & \multirow{2}{*}{$\stackrel{\mathrm{H} /}{\mathrm{L}}$} & \multicolumn{5}{|c|}{ Tegangan Pada Tian Pengujian Port Analog (V) } \\
\hline & & & 0 & 1 & 2 & 3 & 4 \\
\hline \multirow{2}{*}{ A0 } & \multirow{6}{*}{$5 \mathrm{~V}$} & $\mathrm{H}$ & 4,5 & 4,5 & 4,5 & 4,5 & 4,5 \\
\hline & & L & 0 & 0 & 0 & 0 & 0 \\
\hline \multirow{2}{*}{ A1 } & & $\mathrm{H}$ & 0 & 0 & 0 & 0 & 0 \\
\hline & & $\mathrm{L}$ & 0 & 0 & 0 & 0 & 0 \\
\hline \multirow{2}{*}{$\mathrm{A} 2$} & & $\mathrm{H}$ & 4.75 & 4.75 & 4.75 & 4.75 & 4.75 \\
\hline & & $\mathrm{L}$ & 0 & 0 & 0 & 0 & 0 \\
\hline
\end{tabular}

\begin{tabular}{|c|c|c|c|c|c|c|c|}
\hline \multirow{2}{*}{ Pin } & \multirow{2}{*}{ Vin } & \multirow{2}{*}{$\begin{array}{c}\mathrm{H} / \\
\mathrm{L}\end{array}$} & \multicolumn{5}{|c|}{$\begin{array}{c}\text { Tegangan Pada Tiap Pengujian Port Komunikasi } \\
\text { (V) }\end{array}$} \\
\hline & & & 0 & 1 & 2 & 3 & 4 \\
\hline \multirow{2}{*}{$\mathrm{R} \times 0$} & \multirow{4}{*}{$5 \mathrm{~V}$} & $\mathrm{H}$ & 4,6 & 4,6 & 4,6 & 4,6 & 4,6 \\
\hline & & $\mathrm{L}$ & 0 & 0 & 0 & 0 & 0 \\
\hline \multirow{2}{*}{$\mathrm{Tx} 0$} & & $\mathrm{H}$ & 4,6 & 4,6 & 4,6 & 4,6 & 4,6 \\
\hline & & $\mathrm{L}$ & 0 & 0 & 0 & 0 & 0 \\
\hline
\end{tabular}

\section{Rangkaian Modul RFID}

Pengukuran RFID disini adalah pengukuran jarak baca dari dari kartu smart card, pengukurannya ditunjukkan pada tabel 3.

Tabel 3.3 Pengukuran kartu Smart card

\begin{tabular}{|c|c|}
\hline Jarak Baca & Keterangan \\
\hline $1 \mathrm{~cm}$ & Terbaca \\
\hline $2 \mathrm{~cm}$ & Terbaca \\
\hline $3 \mathrm{~cm}$ & Terbaca \\
\hline $4 \mathrm{~cm}$ & Terbaca \\
\hline $5 \mathrm{~cm}$ & Terbaca \\
\hline $6 \mathrm{~cm}$ & Terbaca \\
\hline $7 \mathrm{~cm}$ & Tidak Terbaca \\
\hline $8 \mathrm{~cm}$ & Tidak Terbaca \\
\hline $9 \mathrm{~cm}$ & Tidak Terbaca \\
\hline $10 \mathrm{~cm}$ & Tidak Terbaca \\
\hline
\end{tabular}

Ketika smartcard yang didekatkan cocok dengan data yang ada di mikro, maka mikro akan mendapat inputan data dan jumlah pulsa akan bertambah sehingga terlihat pada tampilan LCD 20x4, pada posisi ini katub selenoid valve akan terbuka maka air dapat mengalir.

Ketika smartcard yang didekatkan tidal cocok dengan data yang ada di mikro, maka mikro tidak akan mendapat inputan data dan jumlah pulsa akan tetap sehingga terlihat pada tampilan LCD 20x4 pulsa tetap. 


\section{Pengujian Jumlah Liter Air}

Pengujian jumlah liter air dimaksudkan untuk mengetahui tingkat keakurasian alat dalam membaca jumlah liter air, untuk itu diambil beberapa sampel pengukuran sebagai berikut :

Tabel 4. Pengukuran dengan aliran konstan

\begin{tabular}{|c|c|c|}
\hline \multicolumn{2}{|c|}{$\begin{array}{c}\text { Pengujian Dalam Keadaan aAliran Air } \\
\text { Konstan }\end{array}$} & \multirow{2}{*}{ Prosentase error } \\
\hline Nyata (1) & LCD (1) & $2 \%$ \\
\hline 1,00 & 1,02 & $3 \%$ \\
\hline 1,00 & 1,03 & $2 \%$ \\
\hline 1,00 & 1,02 & $3 \%$ \\
\hline 1,01 & 1,04 & $2 \%$ \\
\hline 1,00 & 1,02 & \\
\hline
\end{tabular}

Tabel 5. Pengukuran dengan aliran tidak konstan

\begin{tabular}{|c|c|c|}
\hline \multicolumn{2}{|c|}{$\begin{array}{c}\text { Pengujian Dalam Keadaan Aliran Air } \\
\text { tidak Konstan }\end{array}$} & \multirow{2}{*}{ Prosentase error } \\
\cline { 1 - 2 } Nyata (1) & LCD (1) & \\
\hline 1,03 & 1,02 & $1 \%$ \\
\hline 1,05 & 1,04 & $2 \%$ \\
\hline 1,05 & 1,03 & $2 \%$ \\
\hline 1,07 & 1,04 & $3 \%$ \\
\hline 1,04 & 1,03 & $1 \%$ \\
\hline
\end{tabular}

\section{KESIMPULAN}

- Smartcard mempunyai fungsi sebagai pengendali jumlah liter air yang akan digunakan pada Meteran Air Digital Prabayar, dengan mengisikan jumlah liter tertentu pada kartu dan membacakan pada alat maka akan mendapat jumlah liter yang dimasukan dan membatasi pemakaian air sesuai jumlah liter ang dimasukan.

- Penerapan sistem prabayar pada meteran air digital prabayar dapat mengatasi masalah penunggakan pembayaran dalam langganan air pada PDAM.

- Water flow Sensor berfungsi sebagai penghitung jumlah liter air yang telah lewat/ terpakai dengan tingkat kesalahan 1,8\%-2,4\%.

\section{DAFTAR PUSTAKA}

1. Amalia, Iwan, Drajat, Aplikasi Smart Card sebagai Pengunci Elektronis pada Smart Home.Semarang: Universitas Diponegoro.

2. Dedy, Aplikasi smart card sebagai kartu prabayar internet. Semarang: Universitas Diponegoro.

3. Kadir, Abdul. 2012. Panduan Praktis Mempelajari Aplikasi Mikrokontroler \& Pemrograman Menggunakan Arduino. Yogyakarta: Andi

4. Malvino. 1994. Prinsip-prinsip Elektronika. Jakarta: Erlangga

5. Subiono, Aghus, R Rizal. Kartu Cerdas Tanpa Kontak (Contactless Smartcard) Pada Sistem Parkir Berlangganan. Semarang: Universitas Diponegoro

6. Yulianto, Andik. Membaca Kartu RFID Mifare 13.56MHz dengan CR-013F, ATMega 128 dan Bascom (bag.1). 